\title{
Investigating Factors Affecting Knowledge Management Practices in Public Sectors
}

\author{
Subashini Ganapathy ${ }^{1}$, Zulkefli Mansor ${ }^{2}$, Kamsuriah Ahmad $^{3}$ \\ Faculty of Information Science and Technology, National University of Malaysia Bangi, Selangor, Malaysia
}

\begin{abstract}
Knowledge Management (KM) is a systematic approach in creating, sharing, using and managing information effectively sustain knowledge regardless public or private organizations. It helps organizations to make better decision making in order to achieve the goals and increase the productivity. However, many public organizations are still facing challenges to adopt knowledge management practices compared to private organization due to lack of awareness. They are not aware of the influenced factors such as people, process, and technology. Therefore, this paper identifies influencing factors that contributed to the successful KM practices in public sectors. This study employs quantitative approaches by distributing a set of questionnaires to 83 IT practitioners in public organizations. 63 returned responses were analyzed using the Rasch Measurement Model. The findings indicated that there is a lack of participation amongst the staff in practicing efficient knowledge management due to they are still not ready to accept changes to the new system, lack of exposure and behavior. In addition, looking at critical success factor such as on the human resources (HR), there is a lack of encouragement such as rewards and recognition given to employees who practices $K M$ in the organization. As a result, this paper highlights the most influential factors for effective knowledge management practices in terms of people, process and technology. We hope that the results can be used as a guideline to rectify the challenges in KM practices especially in the public organizations.
\end{abstract}

Keywords-Critical success factors; influencing factors; knowledge management; public sector

\section{INTRODUCTION}

Knowledge Management (KM) is a systematic effort to encourage and facilitate the flow of knowledge within the organization to speed up organizational learning [1]. Knowledge-based information plays a very important role in the public sector as well as in the private sector. Public administration especially marked as an important element in any nation because of its contribution to economic growth and development of a country as compared. Basically, public organizations showing its tendencies to culture and challenged when it comes to introduction of new management initiatives. Implementation of $\mathrm{KM}$ in the public sector is still not clear even longstanding and there is resistance to change, particularly from the perspective of the individual [2].

To be more precise, there is resistance to change, particularly from the perspective of the individual to any related KM practices or system. As concerned, there is evidence showed that more studies done in private sectors with a small contribution towards the public sector [3]. It is

Sponsored by Faculty of Information Science and Technology, Nationa University of Malaysia (UKM) also found that [1] research on public sector is relatively less compared to the private sector.

Successful companies are those who are consistently practicing, creating, sharing, storing and disseminating source of knowledge properly. These success rates become more precise with the adaptation of new technologies and products [4]. Considering in Malaysia, various studies have been conducted to determine the factors that influence the practice of KM. However, understanding KM in Malaysian context is still difficult due to its limited studies [5]. Among the factors that were studied in terms of human resources, confidence of individuals and organizational culture, technology, individual performance, awareness and understanding of people, leadership and strategy, the involvement of top management and external factors related to external influences. However, most of the studies have related to factors affecting the KM in the private sector compared to the public sectors.

A study by [2] highlighted that, the practice of KM in the public sector is still weak. Secondly, it is found that there is less appropriate criteria are examined to determine the factors that influence $\mathrm{KM}$ practices the most. Taking this into consideration, this current study is to further explore the KM practices in Malaysia especially in the public sector. And a thorough study will be done to get to know the most influenced factors that contributing to the success of $\mathrm{KM}$ in the public sector today so that it becomes a guide to all parties.

\section{RELATED WORKS}

The concept of knowledge management (KM) is an important activity to be carried out effectively by the organization. We reside in a world of rapid change driven by globalization, the knowledge-based economy combined with the development of information, communication and technology (ICT). This transformation, however, not solely poses some challenges, however conjointly offers opportunities for each private and public sector. KM focuses on the effective ways to manage knowledge to acquire competitive advantage [6] and marked as an important aspect for organizations to have efficient knowledge resources managing round the world. Most of the huge companies in the private sector have been actively taking initiatives to adopt and practice KM along with tool and techniques. Determination in the public sector in terms of KM initiatives is less compared to the private sector [7].

The importance of managing knowledge is classified to whom to share, what is to be shared, how it is to be shared, and ultimately sharing and using it. Managing information or 
knowledge fabricates benefits when the knowledge is shared, used and reused. The benefits of KM practice can be seen effectively when there is an atmosphere of motivation and trust for people to share and use knowledge, when there are systematic processes to find and create knowledge, and, when needed. This process is supported by adequate technology to store and make knowledge relatively simple to find and share. With regards to this, understanding the KM in the Malaysian context is difficult because the study was limited [5]. Knowledge management (KM) was born in accordance with the initial development of the "Multimedia Super Corridor (MSC)" in the 1990s in Malaysia.

Most of the public and private sector organizations have already adapted the concept of $\mathrm{KM}$ in Malaysia. Draft regulation regarding $\mathrm{KM}$ has been in practice in most of the private sector than in the public sector, such as MIMOS, Siemens, Bank Negara Malaysia, Nokia Malaysia, Telekom, Tenaga Nasional and Petronas [8]. In fact, there are several KM systems were used as a support for the creation, sharing, storage and dissemination of knowledge. Malaysia, like other countries that practice $\mathrm{KM}$ faced various obstacles and challenge. And those challenges need to be addressed and further research to solve effectively. In that case, various studies have been conducted in both public and private sector organizations. Consequently, researchers have identified several obstacles that are common in both sectors. Organizational changes at the beginning is difficult, the willingness of the organization should be assessed prior to proceeding with any initiative [9].

One of the major obstacles in practicing $\mathrm{KM}$ is the behavior of the workers themselves, and one of the sub-factor that influence behavior is that, there's a lack of sharing culture with colleagues. On the other hand, there are some employees who are reluctant to ask their colleagues for information and knowledge. The reason is that, they might be thinking that the colleagues will look down if they ask so because of low knowledge [10]. Cultural exchange is also a challenge faced by most organizations. KM successful practice requires an open culture that encourages knowledge sharing. Individual factors play as an important role [11] in the process of cultural change [9].

In another point of view, evolution of Information Communication Technology (ICT) turns into new challenge in KM implementation. Speedy growth especially in ICT produces large amounts of information around the world requires organizations to align their knowledge and technology in this direction [12]. Other than that, another critical success factor such as lack of top management support also found to be challenged in the use and practice of KM. With the full support of the management, organization can even provide a favorable environment [13] that will encourage workers to have more commitment and will promote knowledge creating practice to form a better organizational performance. Conversely, without a proper involvement and supports from top management would also cause inefficient practices [14].

Based on the current literature review, limitations of technology are found out as an challenge by some researchers because of many processes require information technology
(IT) to KM practices. Infrastructure information systems rely on the use of network technology such as the internet, lotus notes and communications systems for transferring knowledge. This is a major contributor to the application and dissemination of knowledge [8]. It can be concluded that the technology is important for the efficient of overall KM regulation system.

Apart from that, critical success factor such as organizational structure was also said to be one of the factors which influence KM practices [15]. Organizational structure plays important role in the knowledge conversion. Organization need to have favorable structure [16] in order to implement KM successfully. Team size most likely affect the performance of KM practices in the overall. Bigger team size may contribute to efficient knowledge sharing performance. Roles and responsibility of the leader were also playing roles in promoting good leadership styles in giving guidance for employees to practice KM effectively.

\section{RESEARCH METHODOLOGY}

This study focuses on middle management and top management, including their processes and activities regarding $\mathrm{KM}$ practices. A quantitative approach was conducted through a questionnaire survey. One of the focuses of this paper is on the outcomes of the questionnaire survey after analysis has completed. Therefore, the questions were categorized into three main aspects which are people, process, and technology. The questionnaires were distributed to the public organization as per targeted sample. In this case, five ministries have been chosen randomly as a target to study the factors influence the public sector. In addition, an online version of the questionnaires was distributed. Respondents who responded were the quality managers, information technology personnel and personnel involved indirectly in the $\mathrm{KM}$ in the ministry.

The questionnaires will be distributed to check the KM practices in the organization through survey. The questionnaires were developed based on the following key process area as per shown in Fig. 1.

The questionnaires were developed based on the following key process area as per shown in Fig. 1. The questionnaires will be distributed to check the $\mathrm{KM}$ practices in the organization through survey. There is a total of 24 items developed based on the people, technology and process key area. People criteria were assessed from organizational culture in terms on the employee's (trust, chances, confident, willingness to accept changes, commitment, participation, and teamwork skills), organizational structure (team size, community of practice, leadership roles) and human resource (resources, time management, promotion, and rewards) perspectives. While, technology criteria, were evaluated based on the technology infrastructure that supports the practices and Information Technology (IT) tools that being used to perform KM practices. Process criteria scoped to its knowledge creation, storing, sharing and knowledge application (dissemination).

The research question (RQ) for the study is:

RQ1: What are the most factors influencing KM practices in the organization? 


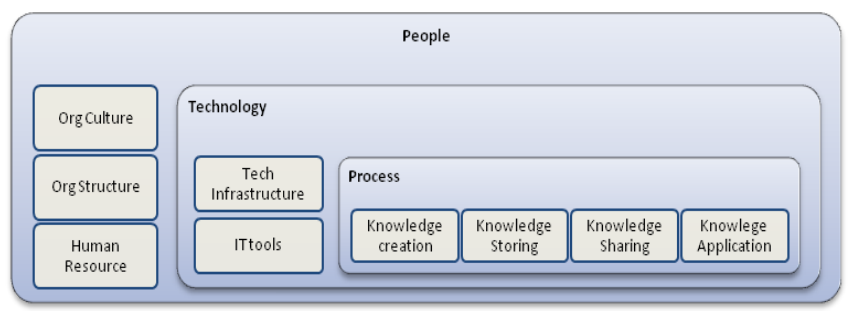

Fig. 1. Questionnaires Criteria.

The data retrieved will be analyzed using Rasch model. Rasch statistical analysis used because of its ideal statistical techniques that allow the scales to be modified [17] by removing unreliable items. In that case, WINSTEPS software used to analyze the data. INFIT and outfit statistics were used to measure the fit of the items in the Rasch model. Possible attributes defined the probability of response in an item [18]. The Rasch model is expected to measure the KM practices based on the influencing factors. The similar approach will be used to evaluate the KM practices in the organizations in this study.

\section{A. Normality Test}

This normality test is used to see the distribution of the sample size. This is important to see the sample collected falls within the range and its Skewness as well as Kurtosis. According to [19], values that fall within the range of -3 to +3 for the Kurtosis test, and -2 to +2 for the Skewness test is considered within the normal range. Therefore, the normality of this study is normal. Table II shows the mean, standard deviation, Skewness and Kurtosis of the sample gathered.

\section{B. Reliability Test}

Data were analyzed using Winstep Rasch analysis software. To test the internal consistency of the questionnaires, the results of the analysis showed that the value of Cronbach's Alpha $(\alpha)$ is 0.68 as shown in Table I below. The value of Cronbach's alpha for all constructs must be above 0.6. Ideally the Cronbach's alpha should be above 0.7 . Since the current value is within 0.65 and 0.70 , it is minimally acceptable [20].

For summary statistic, INFIT ZSTD for Person as well as Item is close to 0 and MNSQ are close to 1.0 , so the data gathered to consider fitting the model. An item MNSQ fit statistic of 1.0 meaning that the item was perfectly fit the expected model. Table II shows the fits statistic for data fits. INFIT ZSTD for the values for all items are lesser than 1.5, so the all items are considered acceptable in this study. Parameter level ranges between $0.5-1.5$ as shown in Table II considered productive for measurement hence it is reliable.

TABLE. I. SUMMARY STATISTICS

\begin{tabular}{|c|c|c|c|c|c|c|c|c|}
\hline & \multirow{2}{*}{ TOTAL SCORE } & \multirow{2}{*}{ COUNT } & \multirow{2}{*}{ MEASURE } & \multirow{2}{*}{ MODEL S.E } & \multicolumn{2}{|l|}{ INFIT } & \multicolumn{2}{|c|}{ OUTFIT } \\
\hline & & & & & $M N S Q$ & ZSTD & MNSQ & ZSTD \\
\hline MEAN & 87.0 & 25.0 & 0.48 & 0.23 & 1.02 & -.27 & 1.01 & -.24 \\
\hline SEM & 1.0 & .0 & 0.05 & .00 & .07 & .27 & .07 & .26 \\
\hline P.SD & 7.8 & .0 & 0.43 & .01 & .58 & 2.12 & .55 & 2.03 \\
\hline S.SD & 7.8 & .0 & 0.43 & .01 & .58 & 2.14 & .55 & 2.05 \\
\hline MAX & 103.0 & 25.0 & 1.45 & .27 & 2.38 & 3.96 & 2.26 & 3.65 \\
\hline MIN & 71.0 & 25.0 & -.32 & .21 & .20 & -4.41 & .20 & -4.45 \\
\hline \multicolumn{9}{|c|}{$\begin{array}{l}\text { REAL RMSE } .26 \text { TRUE SD } .33 \text { SEPARATION } 1.27 \text { PERSON RELIABILITY } .62 \\
\text { MODEL RMSE } .23 \text { TRUE SD } .36 \text { SEPARATION } 1.52 \text { PERSON RELIABILITY } .70 \\
\text { S.E. OF PERSON MEAN }=.05\end{array}$} \\
\hline \multicolumn{9}{|c|}{ PERSON RAW SCORE-TO-MEASURE CORREI_ATION $=100$} \\
\hline
\end{tabular}

TABLE. II. Fit StATistics

\begin{tabular}{|c|c|c|c|c|c|c|c|c|}
\hline & \multirow{2}{*}{ TOTAL SCORE } & \multirow{2}{*}{ COUNT } & \multirow{2}{*}{ MEASURE } & \multirow{2}{*}{ MODEL S.E } & \multicolumn{2}{|l|}{ INFIT } & \multicolumn{2}{|c|}{ OUTFIT } \\
\hline & & & & & $M N S Q$ & ZSTD & $M N S Q$ & ZSTD \\
\hline MEAN & 221.0 & 63.0 & 0.00 & 0.15 & 1.01 & .08 & 1.02 & .13 \\
\hline SEM & 5.1 & .0 & 0.11 & .00 & .03 & .14 & .03 & .15 \\
\hline P.SD & 24.7 & .0 & 0.55 & .01 & .12 & .67 & .13 & .70 \\
\hline S.SD & 25.2 & .0 & 0.56 & .01 & .12 & .69 & .13 & .72 \\
\hline MAX & 269.0 & 63.0 & 0.92 & .18 & 1.32 & 1.70 & 1.34 & 1.82 \\
\hline MIN. & 177.0 & 63.0 & -1.19 & .14 & .85 & -.90 & .81 & -1.08 \\
\hline \multicolumn{9}{|c|}{$\begin{array}{l}\text { REAL RMSE } .15 \text { TRUE SD } .52 \text { SEPARATION } 3.40 \text { ITEM RELIABILITY } .92 \\
\text { MODEL RMSE } .15 \text { TRUE SD } .53 \text { SEPARATION } 3.50 \text { ITEM RELIABILITY } .92 \\
\text { S.E. OF ITEM MEAN }=.11\end{array}$} \\
\hline $\begin{array}{l}\text { ITEM R } \\
\text { UMEAN }\end{array}$ & $\begin{array}{l}\text { TO-MEASURE CO } \\
\text { CALE }=1.0000\end{array}$ & ELATION & & & & & & \\
\hline
\end{tabular}




\section{RESULTS AND FINDINGS}

This study used five point Likert scale (strongly disagree, disagree, neutral, agree and strongly agree) type of questions and the respondent have to rate the statement from strongly disagree to strongly agree scaling. A survey was distributed to 83 respondents and returned by 63 with the yielding rate of $76.8 \%$. Five ministries responded. The entire ministry is under the category of 100-500 employees. Table III below shows the demographic profile of the respondents.

In this study, there are a total of 28 respondents which consist of (44.4\%) female respondents and $35(55.6 \%)$ male respondents. The percentage shows that the male respondents are much higher than the female respondents. Basically, most of the respondents are from the Information Technology department, which compromise $44.4 \%$ and $33.3 \%$ of human resource department. The rest of the unit were also indirectly play roles in knowledge management practices since they are also in charge of managing knowledge and information on the organization in particular division or department. There are respondents from six departments such as finance, IT, accounts, human resource and the other two from the top management department. All the participants were from middle level as well as manager's post. These profiles of participants provide valuable information about the context in which, the research findings are applicable. From the response, 28 employees are from the Information Technology (IT) department. Most of the employees who responded the survey are from the IT post $(44.4 \%)$ such as secretary, secretary, assistant, IT officer and IT assistants. These four positions basically play roles in information management and indirectly involved in terms of KM practices in their organization. Table III above represents the actual information about the positions held by the participants in the five ministries from eight departments.

TABLE. III. DEMographic ProfiLe OF ReSPondents (N=63)

\begin{tabular}{|c|c|c|c|}
\hline Variable & Category & Frequency & Percentage \\
\hline \multirow[t]{2}{*}{ Gender } & $\begin{array}{l}\text { Male } \\
\text { Female }\end{array}$ & $\begin{array}{l}35 \\
28 \\
\end{array}$ & $\begin{array}{l}55.6 \% \\
44.4 \%\end{array}$ \\
\hline & Total & 63 & $100.0 \%$ \\
\hline \multirow[t]{2}{*}{ Age group } & $\begin{array}{l}25 \text { to } 29 \\
30 \text { to } 34 \\
35 \text { to } 39 \\
40 \text { to } 44 \\
45 \text { to } 49 \\
50 \& \text { above }\end{array}$ & $\begin{array}{l}12 \\
19 \\
11 \\
5 \\
4 \\
12\end{array}$ & $\begin{array}{l}19.0 \% \\
30.2 \% \\
17.5 \% \\
7.9 \% \\
6.3 \% \\
19.0 \%\end{array}$ \\
\hline & Total & 63 & $100.0 \%$ \\
\hline \multirow[t]{2}{*}{ Ministry } & $\begin{array}{l}\text { Ministry of Works } \\
\text { Housing \& Local Government } \\
\text { Federal \& Regional } \\
\text { Science, Technology \& Innovation } \\
\text { Rural \& Regional Development }\end{array}$ & $\begin{array}{l}29 \\
8 \\
7 \\
11 \\
8 \\
\end{array}$ & $\begin{array}{l}46.0 \% \\
12.7 \% \\
11.1 \% \\
17.5 \% \\
12.7 \% \\
\end{array}$ \\
\hline & Total & 63 & $100.0 \%$ \\
\hline \multirow[t]{2}{*}{$\begin{array}{l}\text { Year of Experience in } \\
\text { Ministry }\end{array}$} & $\begin{array}{l}1-3 \text { years } \\
3-5 \text { years } \\
5-7 \text { years } \\
7-10 \text { years } \\
10-14 \text { years } \\
\text { More than } 15 \text { years } \\
\end{array}$ & $\begin{array}{l}18 \\
17 \\
3 \\
13 \\
8 \\
4\end{array}$ & $\begin{array}{l}28.6 \% \\
27.0 \% \\
4.8 \% \\
20.6 \% \\
12.7 \% \\
6.3 \% \\
\end{array}$ \\
\hline & Total & 63 & $100.0 \%$ \\
\hline \multirow[t]{2}{*}{ Position } & $\begin{array}{l}\text { Secretary } \\
\text { Secretary Assistant } \\
\text { Chief IT Officer } \\
\text { IT Officer } \\
\text { IT Assistant } \\
\text { Administrative Officer } \\
\text { Administrative Assistant }\end{array}$ & $\begin{array}{l}3 \\
12 \\
4 \\
15 \\
7 \\
11 \\
11 \\
\end{array}$ & \begin{tabular}{l|}
$4.8 \%$ \\
$19.0 \%$ \\
$6.3 \%$ \\
$23.8 \%$ \\
$11.1 \%$ \\
$17.5 \%$ \\
$17.5 \%$ \\
\end{tabular} \\
\hline & Total & 63 & $100.0 \%$ \\
\hline \multirow[t]{2}{*}{ Department } & $\begin{array}{l}\text { Secretary Chief Office } \\
\text { Deputy Secretary Chief Office } \\
\text { Information Technology } \\
\text { Account } \\
\text { Finance } \\
\text { Human Resource }\end{array}$ & $\begin{array}{l}2 \\
2 \\
28 \\
5 \\
5 \\
21\end{array}$ & \begin{tabular}{l|l}
$3.2 \%$ \\
$3.2 \%$ \\
$44.4 \%$ \\
$7.9 \%$ \\
$7.9 \%$ \\
$33.3 \%$ \\
\end{tabular} \\
\hline & Total & 63 & $100.0 \%$ \\
\hline
\end{tabular}


Most of the staff with the percentage of (30.2\%) are from 30 to 34 years of age category and $19.0 \%$ is in 25 to 29 years of age category. It implies that the young generation is in the managerial positions. Therefore, for them, it is easy to manage and capture the knowledge management with the world trend. Besides that, a number of $44.4 \%$ of the respondent has more than 5 years of experience in their organization. In that figure, almost $20.6 \%$ of them have 7 to 10 years of experience. Therefore, the results indicate that the respondents have enough experience and knowledge about their position and practices. As a result, respondent is aware of the management structure of their organization. In fact, implementing the KM initiatives in these organizations supposed to be easier because of the employee's long experience in the ministry. The reason why KM remains weak is to be further explored.

In order to know the opinion towards KM, the respondents were asked whether they know about KM in general at the first place. This question was to ensure that the respondents have some sort of awareness or grasp of KM concepts. Almost $70.6 \%$ have answered that they have heard of this concept and remaining $29.4 \%$ have not heard about it. When asked about whether they are aware of KM practices in their organization, half of the respondents are aware of the practices, while $29.0 \%$ are not aware, and the remaining respondents are not sure whether the practices are there in their organization. Similarly, the perception on the level of $\mathrm{KM}$ practices in their organization is still puzzled from the respondent's perspective. Almost 12 respondents $(35.3 \%)$ said that they are not sure where their KM practices are up to. Almost $20.6 \%$ of the respondents are not sure about the level of KM practices in their organizations. This is due to lack of individual commitment to the organization. The other reason could be that they are not given any awareness on the importance of KM.

\section{A. People}

In this section, the respondent was asked to agree with the statement in terms of people or individual's perspective in the organization. The responses are quite moderate and fall into neutral to agree level. The respondents were asked to rate their level of agreement based on the organizational culture, organizational structure, and human resource (HR) perspective and how these factors influence their KM practices.

1) Organizational culture: Organizational factors were evaluated based on the opportunity, trust and encouragement given to participate in $\mathrm{KM}$ practices. Almost $47.1 \%$ are agreeing with the statement and this showed that they are given some sort of motivation as well as encouragement to participate in KM. Fig. 2 below shows the statistic on the level of agreement in terms of trust, encouragement and opportunity given in practicing KM.

In another view, when asked about the radius of a participation sub-factor in KM practices, most of the respondent agrees $(35.3 \%)$ that there is less participation inside the organization, $5.9 \%$ strongly agree with the statement. Almost $20.6 \%$ are not agreeing with the statement. It is found that, mostly the employees are not willing to accept changes of the system. Additionally, in terms of team cooperation, most of them (28 respondent) are agreed that there is teamwork in solving certain issues in the organization related to $\mathrm{KM}$ practices.

2) Organizational structure: On the other hand, the respondent was asked to rate the agreement on the size of the group, community of practice and roles and responsibility related to KM practices. The respondent was asked whether the bigger size group plays an important role in knowledge sharing practices in the organization, and most of them $(44.1 \%)$ said that group size does give impact to knowledge sharing. The bigger group promotes positive knowledge sharing. Only 3 people (8.8\%) don't agree with the statement. Apart from this, in terms of practicing community of practice (COP), most respondents answered in a moderate manner which is $41.2 \%$. Almost $29.4 \%$ have agreed with the statement that the roles and responsibilities of knowledge officer don't practice the KM practices.

3) Human Resource (HR): Looking at the human resource management (HRM) perspectives, management actually provides resources and time management to enroll in the learning and sharing exercises for motivation. Promotion or appraisal is given to their work commitment. However, when asked about providing rewards and recognition of KM related activities. The response is just moderate $(50 \%)$ in terms of giving recognition. From this, it can be concluded that the management is less giving the reward to the employee who actively practice KM. Without proper recognition, the level of commitment from the employee towards KM practices indirectly effects the overall participations in the organization.

\section{B. Technology}

In the perception of technology perspective, almost $50 \%$ of the respondents were agreed that the organization has cuttingedge Information Communication Technology (ICT) infrastructures that support KM initiative at first place. E-mail was used as a primary resource for knowledge sharing. Almost $41.2 \%$ respondent agreed that they are using E-mail in practicing KM. The employees are mainly using E-mail option for creating, sharing and distribute knowledge and information among colleagues.

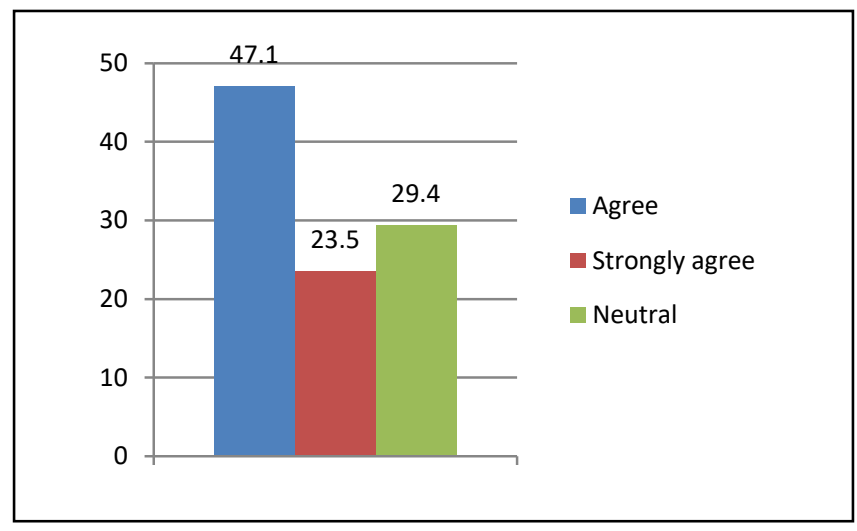

Fig. 2. Level of Trust, Encouragement and Opportunity by Respondents. 
Fig. 3 above shows the level of agreement in using email and groupware as one of the KM practices option. It is found that the organizations are less using the groupware for knowledge sharing.

The internet was mostly used with (70.6\%) to support KM practices and intranet $(64.7 \%)$ for knowledge storing and sharing activity. Knowledge Management System (KMS) was particularly used in some of the studied organization for storing information and knowledge. The other tools used are business intelligence tools and WhatsApp group. Fig. 4 below shows the IT tools in practicing KM.

\section{Process}

This section with regards to KM processes which is knowledge creation, storing, sharing and knowledge dissemination. Basically, there is knowledge creation in the organization with the percentage of $79.4 \%$. Knowledge created in a formal way by having frequent meeting and brainstorming session among the employees in the organization. Knowledge storing activities are formal and following the standard where most of the employees are using some basic tools such as data management system as well as cloud to store the information or knowledge. Knowledge sharing happens in an informal way. It is found that there is selective knowledge sharing activity with certain individual with a range of $17.6 \%$ in the organization. To be more precise, information, skills or expertise is shared with some employees only.

Fig. 5 above shows the full rate of knowledge sharing criteria. Additionally, for knowledge dissemination activities are quite interesting where the knowledge dissemination happens in an informal way within the group (44.1\%).

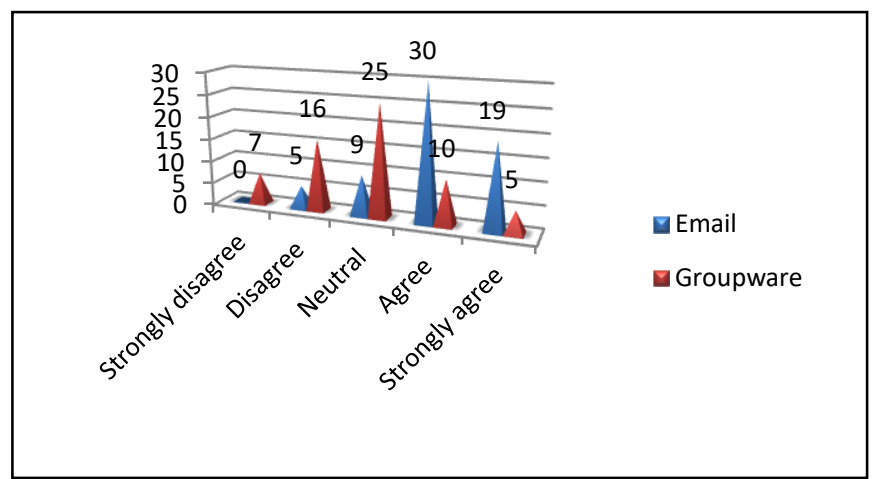

Fig. 3. Email and Groupware usages.

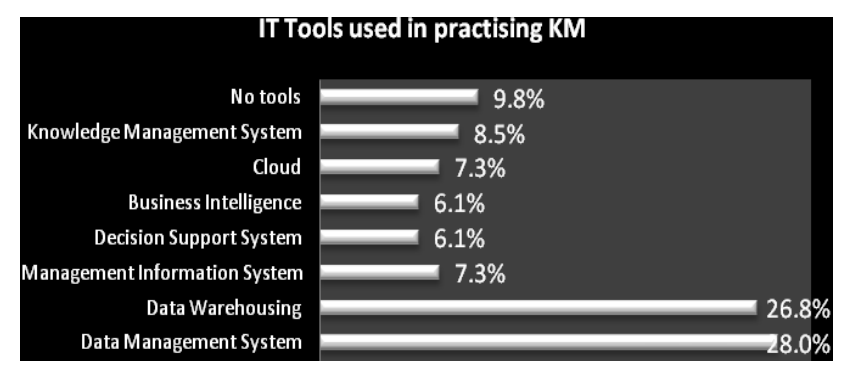

Fig. 4. ICT Tools.

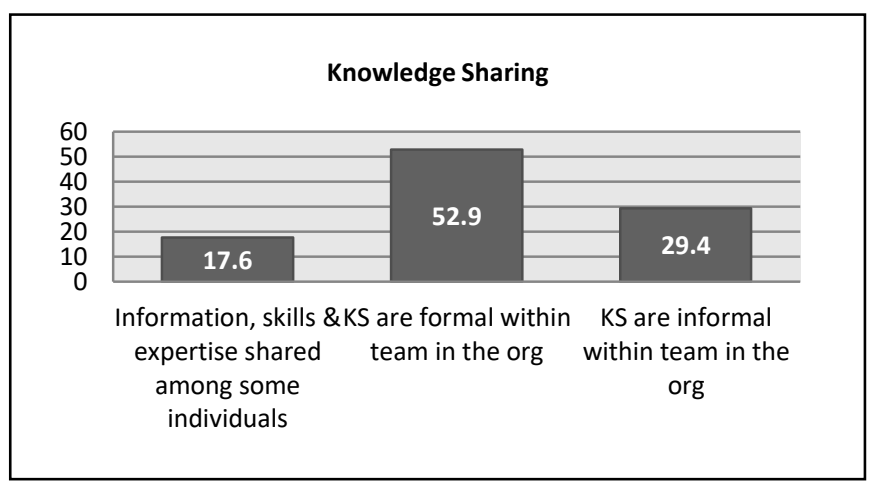

Fig. 5. Knowledge Sharing Activity.

Additionally, for Rasch analysis, an item-person map (Fig. 6) used 24 items during the initial analysis. The map stipulates that the sample gathered overall was satisfactory. The most difficult item was "accept changes" with item difficulty 0.92 , while the easiest item was "teamwork" with 1.19 .

Fig. 7 shows the overall category of scaling rate of this study. It is observed that category between rating 2 (disagree) and rating 3 (Neutral) distance is 0.31 (Table IV). This stipulated that these two categories are less probable to be discovered. This is due to fact that the respondents are given many categories as an option [10].

There are five factors (Fig. 8) that influenced most of the employees in terms of $\mathrm{KM}$ practices in their organization which is the readiness to accept the new system, less reward and recognition toward practicing KM from HR perspectives.

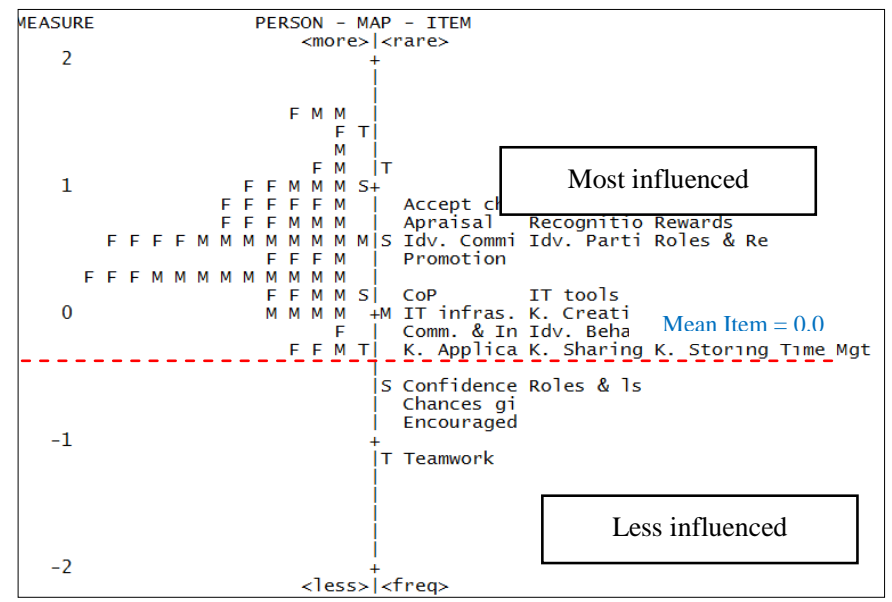

Fig. 6. Person-Item Map.

TABLE. IV. CATEGORY STRUCTURE SUMMARY

\begin{tabular}{|l|l|l|l|l|}
\hline Category & Score & $\begin{array}{l}\text { Observed } \\
\text { Count }(\%)\end{array}$ & $\begin{array}{l}\text { Outfit } \\
\text { MNSQ }\end{array}$ & $\begin{array}{l}\text { Threshold } \\
\text { Andrich }\end{array}$ \\
\hline Strongly Disagree & 1 & -0.11 & 1.16 & NONE \\
\hline Disagree & 2 & 0.22 & 1.29 & -1.26 \\
\hline Neutral & 3 & 0.22 & 0.85 & -0.95 \\
\hline Agree & 4 & 0.74 & 0.87 & 0.38 \\
\hline Strongly Agree & 5 & 1.21 & 0.94 & 1.83 \\
\hline
\end{tabular}




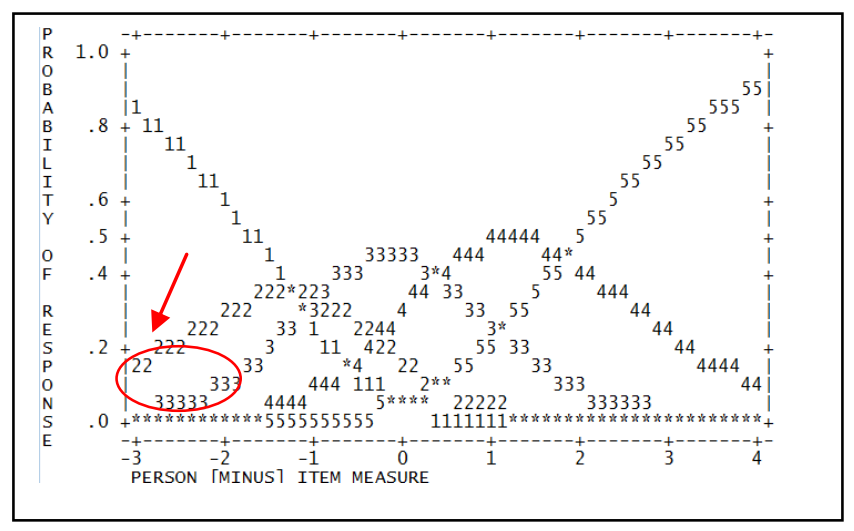

Fig. 7. Category Probability Curves for 5 Scale Rating.

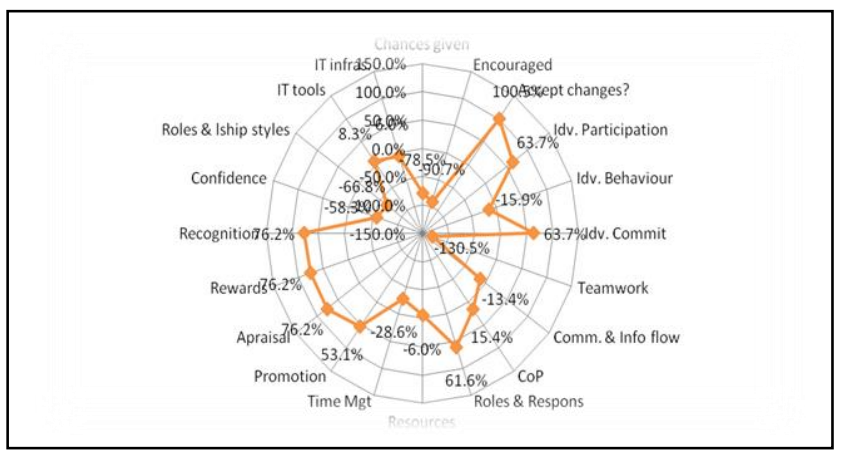

Fig. 8. Factor Influenced KM Practices in the Public Sector.

Lastly, individual participation and commitment was also seen as a difficult sub factor in the organizations. From technological perspectives, there are adequate supporting tools for practicing knowledge. The process of KM seems to be practiced at an earlier stage by some of the employees; however, without collective individual commitment and participation the whole KM initiatives won't be successful in overall. Apart from that knowledge sharing in team seems to be very approachable. Responsibility and roles of Chief Knowledge Officer (CKO), Knowledge consultant (KC), knowledge worker (KW) and knowledge manager (KM) from the study are quite less to see. Without the proper supports and encouragement from top level may influence levels of motivation from the worker's perspective.

\section{CONCLUSIONS}

Based on the findings, almost half of the respondents are aware of KM practices in their organization. However, it is claimed that the respondent faced some challenges while practicing $\mathrm{KM}$ in their daily work. In fact, the level of KM practices in their organization was also unsure. This showed that the respondent is lack of knowledge in up-to-date information about their organization practices of KM. The data revealed there several problems at people's perspective. Basically, these organizations don't have any challenges on the technology where the organization is furnished with supporting infrastructure to practice KM. The process of capturing, creating, storing and sharing in these organizations seems to be properly practiced. From this study, it is found that there are main challenges comes from people's perspective. The problems are briefly described as follows:
- Individual are not ready to accept changes when the new system come.

- Less of individual participation toward KM practices.

- Less individual commitment from individual perspective to KM practices.

- Lack of reward from HR.

- Lack of recognition from HR.

Apart from identifying the critical success factor of KM practices and implementation only, the research on KM practices would be better if the researcher emphasize on some sorts of measurement and identify the level of implementation to overcome challenges that being faced in the organization.

\section{ACKNOWLEDGMENT}

This research was sponsored by Faculty of Information Science and Technology, National University of Malaysia (UKM) under Dana Pecutan Penerbitan PP-FTSM-2019.

\section{REFERENCES}

[1] M. Massaro, J. Dumay, and A. Garlatti, "Public sector knowledge management: A structured literature review," Journal of Knowledge Management, vol. 19(3), pp. 530-558, 2015.

[2] H. Laihonen, and S. Mantyla, "Strategic knowledge management and evolving local government," Journal of Knowledge Management, Vol. 22, no. 1, pp. 219-234, 2018.

[3] O. Syed, and F. Rowland, "Benchmarking knowledge management in a public organisation in Malaysia," An International Journal, Vol. 11, no. 3, pp. $238-266,2004$.

[4] I. Nonaka, and N. Konno, "The concept of "Ba": Building a foundation for knowledge creation. California management review, vol. 40(3), pp. 40-54, 1998.

[5] N. A. Kassim, M. F. Baharuddin, and Z. A Samad, "Knowledge Management Practices and Organizational Performance in Malaysia Government Institution,” International Journal for Infonomics (IJI), vol. 9, no. 4, 2016.

[6] Z. Ahmed, Z. Mansor, K. Ahmad, "An Analysis of Knowledge Management Challenges in Agile Global Software Development," Journal of Telecommunication, Electronic and Computer Engineering., vol. 9, pp. 63-66, 2017.

[7] A. T. Amayah, "Determinants of knowledge sharing in a public sector organization", Journal of Knowledge Management, Vol. 17 No. 3, pp. 454-471, 2013.

[8] J. Moshari, "Knowledge Management Issues in Malaysian Organizations: the Perceptions of Leaders," Journal of Knowledge Management, Economics and Information Technology, vol. 3(5), pp. 1527, 2013.

[9] D. T. Holt, S. E. Bartczak, S. W. Clark, M. R. Trent, "The development of an instrument to measure readiness for knowledge management," Knowledge Management Research \& Practice, vol. 5(2), pp. 75-92, 2007.

[10] A. M. Mills, and T. A. Smith, "Knowledge management and organizational performance: A decomposed view," Journal of knowledge management, vol. 15(1), pp. 156-171, 2011.

[11] A. Tehraninasr, and M. U. R. A. L. I. Raman, "Knowledge management obstacles in Malaysia: An exploratory study," Public Sector ICT Management Review, vol. 3(1), pp. 15-20, 2009.

[12] Abdullah and H. Date, "Public Sector Knowledge Management: A Generic Framework," Public Sector ICT Management Review, Vol. 3(1), pp. 1- 14, 2009.

[13] Singh, S. Kumar, S. Gupta, B. Donatella, and K. Shampy, "Top management knowledge value, knowledge sharing practices, open innovation and organizational performance," Journal of Business Research, 3 May 2019. 
[14] P. Jain, "Knowledge Management In e-Government," Journal of knowledge management practice, vol. 10, no. 4 pp. 1-11, 2009.

[15] Mills, A.M. and T.A. Smith, "Knowledge management and organizational performance: a decomposed view," Journal of knowledge management, vol. 15(1), pp. 156-171, 2011.

[16] M. Z. Islam, S. M. Jasimuddin, and I. Hasan, "The role of technology and socialization in linking organizational context and knowledge conversion: The case of Malaysian Service Organizations," International Journal of Information Management, vol. 37, no. 5, pp. 497-503, 2017.

[17] J. M. Linacre, WINSTEPS Rasch measurement computer program. Chicago: WINSTEPS.com, 2006.
[18] K. Ahmad, M. A. Nazlena, and Z. Suhaila. "An improved course assessment measurement for analyzing learning outcomes performance using Rasch model," Procedia-Social and Behavioral Sciences vol. 18, pp. 442-449, 2011.

[19] D’Agostino, and B. Ralph, "Tests for the normal distribution." In Goodness-of-fit-techniques, pp. 367-420. Routledge, 2017.

[20] R. A. L. F. Griethuijsen, M. W. Eijck, H. Haste, P. J. Brok, N. C. Skinner, and N. Mansour, 'Global patterns in students' views of science and interest in science," Research in Science Education, vol. 45(4), pp. 581-603, 2014. 